\title{
DEMOCRACIA, REPRESENTACIÓN Y PARTICIPACIÓN CIUDADANA, A LA BÚSQUEDA DE UN EQUILIBRIO QUE LA CONSTITUCIÓN NO LOGRÓ
}

FRANCISCO JAVIER DÍAZ REVORIO 
SUMARIO

1. DEMOCRACIA REPRESENTATIVA, INSTITUCIONES DE DEMOCRACIA DIRECTA Y PARTICIPACIÓN CIUDADANA EN LA CONSTITUCIÓN DE 1978: CONTEXTO Y FACTORES CONDICIONANTES. 2. ALGUNAS INSTITUCIONES DE PARTICIPACIÓN CIUDADANA. 2.1. El referéndum. 2.2. La iniciativa legislativa popular. 2.3. El concejo abierto. 2.4. La participación en la Administración. 2.5. El jurado y otras. 3. CUATRO DÉCADAS DESPUÉS, ¿CRISIS DE CONFIANZA? 4. LA TAREA DE LA REGENERACIÓN DEMOCRÁTICA: BUEN GOBIERNO, PARTICIPACIÓN, CONFIANZA. 5. EL DESARROLLO NORMATIVO Y LAS REFORMAS LEGALES. 6. UNA TAREA SIEMPRE PENDIENTE: LA REFORMA CONSTITUCIONAL. 7. CONCLUSIONES. 


\title{
DEMOCRACIA, REPRESENTACIÓN Y PARTICIPACIÓN CIUDADANA, A LA BÚSQUEDA DE UN EQUILIBRIO QUE LA CONSTITUCIÓN NO LOGRÓ
}

\author{
FRANCISCO JAVIER DÍAZ REVORIO \\ Catedrático de Derecho Constitucional \\ Universidad de Castilla-La Mancha
}

\section{DEMOCRACIA REPRESENTATIVA, INSTITUCIONES DE DEMOCRACIA DIRECTA Y PARTICIPACIÓN CIUDADANA EN LA CONSTITUCIÓN DE 1978: CONTEXTO Y FACTORES CONDICIONANTES}

El listón no muy alto, y mucha incertidumbre. Quizá estos dos factores puedan resumir los principales condicionantes que a mi juicio explican la regulación constitucional del modelo de democracia representativa y las instituciones de democracia directa o semidirecta incorporadas a él.

Comenzando por lo primero, cabe entender que, tras cuarenta años de dictadura, la aspiración democrática era muy fuerte, pero la idea que se tenía de la democracia no iba mucho más allá de la posibilidad de elegir periódicamente representantes políticos dentro de una pluralidad de opciones. Eso resultaba, en esencia, más que suficiente. Y quizá por ello, aunque obviamente la Constitución introdujo, como es sabido, algunas instituciones de participación, su protagonismo parece claramente menor que el que ostentan las instituciones representativas, en especial las Cortes Generales. Por lo demás, la regulación de estas instituciones representativas se centra en la elección de sus miembros y en su posterior actuación dentro de la institución asamblearia o parlamento, pero deja de lado en buena medida la relación entre el representante y los representados.

En segundo lugar, hay que tener en cuenta la situación de incertidumbre que se vivió durante el período constituyente, en lo relativo a la estabilidad del sistema

${ }^{1}$ Facultad de Ciencias Jurídicas y Sociales de Toledo. Universidad de Castilla La Mancha. Cobertizo San Pedro Mártir, s/n. 45071 Toledo. Email: FcoJavier.DRevorio@uclm.es 
democrático, así como a la gobernabilidad. La proliferación de partidos inscritos tras el reconocimiento pleno de la libertad de asociación política, cierta dispersión en las formaciones políticas en las propias Cortes constituyentes, y la creencia en la conveniencia de favorecer la estabilidad de los gobiernos como medio para fortalecer el propio sistema democrático y facilitar el necesario desarrollo constitucional y la adopción de decisiones de gobierno e iniciativas legislativas viables, confluyeron en una regulación tendente a favorecer la estabilidad gubernamental y limitar en algún grado las posibilidades de una cierta atomización en el parlamento. De ahí un sistema electoral en el Congreso que, dentro de la proporcionalidad, favorece a las opciones más votadas y dificulta el acceso de las que tienen un porcentaje más bajo de votos. Y quizá de ahí también cierta restricción en las opciones de democracia directa y semidirecta, probablemente buscando dar el protagonismo a las cámaras parlamentarias y al Gobierno, y conseguir una mayor estabilidad de estas instituciones representativas. Quizá había un cierto recelo o desconfianza en cuanto a la madurez democrática de la población, que llevó a restringir sus posibilidades de participación directa, acaso entendiendo que la posibilidad de elegir a representantes políticos era suficiente garantía de la democracia, y un ejercicio abusivo o constante de las vías de participación directa podría devenir en mayores dificultades para el funcionamiento del sistema, o en un cierto caos o debilitamiento de las propias instituciones representativas, o incluso en una mayor debilidad gubernamental.

Por lo demás, desde el punto de vista propiamente teórico o doctrinal, probablemente el debate sobre la democracia directa y la democracia representativa, que ha sido permanente en la historia contemporánea desde Rousseau y Sieyès, y que como veremos ha recobrado protagonismo en los últimos años, era visto por nuestros constituyentes en términos diferentes a los actuales, dando por sentado que la democracia quedaba suficientemente garantizada con el régimen representativo instaurado, pudiendo desempeñar las instituciones de participación directa un papel manifiestamente secundario.

Sea como fuere, en España conviven algunas instituciones participativas de fuerte arraigo y tradición, pero escasa incidencia cuantitativa (concejo abierto, tribunales consuetudinarios), con una menor implantación de otras formas de democracia directa y semidirecta, al menos en términos generales y situándonos en 1978, momento en el que se cerraban décadas de régimen autoritario y no democrático. Frente a algunos Estados que por tradición han dado un peso específico importante a las instituciones de participación directa (siempre suele mencionarse Suiza como ejemplo europeo en esta línea ${ }^{2}$ ), en España esa tradición no existía, pues habiendo sido nuestra democracia contemporánea bastante frágil, es comprensible que nuestra sociedad se haya «conformado» con la posibilidad de elegir represen-

${ }^{2}$ Sobre el referéndum en Suiza, como modelo para analizar las críticas tradicionales a esta institución, véase SÁEnz Royo, E., (2016), «La regulación y la práctica del referéndum en Suiza: un análisis desde las críticas a la institución del referéndum», en Revista de Estudios Políticos, n. ${ }^{\circ} 171$, pp. 71 ss. 
tantes libremente entre opciones plurales, en los momentos de más nivel democrático de nuestra historia. Tampoco cabe olvidar que, por ejemplo, el referéndum o el plebiscito se han utilizado a veces en contextos no democráticos, con ausencia real de libertad, para tratar de buscar una cierta legitimación de algunas decisiones de un poder político autoritario. Esa situación se había dado en España en el período inmediatamente anterior, lo cual, muy probablemente, fue considerado por el constituyente.

Para entender mejor las afirmaciones generales que acabo de realizar, y dado que excede al propósito de este trabajo el análisis de la elección o funcionamiento de las Cortes Generales, me centraré en un breve comentario de las vías de participación ciudadana previstas en la Constitución de 1978.

\section{ALGUNAS INSTITUCIONES DE PARTICIPACIÓN CIUDADANA}

El artículo 23 de la Constitución proclama el derecho de los ciudadanos a participar en los asuntos públicos «directamente o por medio de representantes, libremente elegidos por sufragio universal». Ello quiere decir que la participación directa forma parte del mismo derecho fundamental, y es ubicada en pie de igualdad con la elección de representantes ${ }^{3}$. Por ello, por ejemplo, cualquier restricción injustificada del ejercicio de las instituciones que vamos a analizar contará con las garantías propias de todos los derechos fundamentales, incluyendo el recurso de amparo ante el Tribunal Constitucional.

Con todo, y como he venido apuntando, de la propia regulación constitucional parece deducirse una mayor importancia de los elementos de la democracia representativa, que de las instituciones de democracia directa. Mientras que a la democracia representativa se le dedican numerosos preceptos (prácticamente todo el título III, centrado en los órganos representativos, además de importantes artículos como el art. 6, que considera a los partidos «instrumento fundamental para la participación política»), las instituciones de democracia directa o semidirecta son casi siempre objeto de una regulación breve, o incluso de una mera mención. Para desarrollar la tesis planteada (la de una cierta restricción o limitación constitucional de las vías de participación ciudadana) conviene llevar a cabo un análisis específico de cada una de esas instituciones constitucionalmente reconocidas. Todas han sido objeto ya de un

${ }^{3}$ Sobre este precepto constitucional, con carácter general y como muestra, BASTIDA, F. (1987), «Derecho de participación a través de representantes y función constitucional de los partidos políticos (comentario sobre la idea de representación política en la jurisprudencia del Tribunal Constitucional), en Revista Española de Derecho Constitucional, n. ${ }^{\circ} 21$; Aguilar de Luque, L., y GonzáLeZ Ayala, M.D. (1996), «Artículo 23. El derecho a participar en los asuntos públicos», en Alzaga Villamil, O. (dir.), Comentarios a la Constitución española de 1978, Madrid, Edersa-Cortes Generales. 
abundante tratamiento doctrinal ${ }^{4}$, de manera que en este trabajo, más que hacer un estudio monográfico de la regulación constitucional, me centraré en los aspectos que, en mi opinión, demuestran la idea que se viene defendiendo.

\subsection{El referéndum}

En cualquier sistema constitucional, el referéndum es probablemente la institución de democracia directa por antonomasia, existente en buena parte de los sistemas constitucionales, aunque con variantes importantes ${ }^{5}$. Sin embargo, como se ha dicho,

${ }^{4}$ A título de muestra, véase por ejemplo Torres del Moral, A. (2004), Estado de Derecho y democracia de partidos, Madrid, Universidad Complutense, 2. ${ }^{a}$ ed., en especial pp. 357 ss.; Aguiar DE LuQUe, L. (2000), «Democracia directa e instituciones de democracia directa en el ordenamiento constitucional español», en Trujıllo, G., et alii (dirs.), La experiencia constitucional (1978-2000), Madrid, Centro de Estudios Políticos y Constitucionales, pp. 67 ss.; López Guerra, L. (1994), Introducción al Derecho Constitucional, Valencia, Tirant Lo Blanch, pp. 127 ss.; García RuIZ, L. (2010), Introducción al Derecho Constitucional, Universidad de Cádiz, pp. 187 ss.

${ }^{5}$ Excede de los objetivos del presente trabajo un examen minucioso del Derecho Comparado en la materia. Además de las referencias ya dadas, es muy recomendable el estudio llevado de SÁENZ Royo, E. (2016), «La regulación del referendo en el derecho comparado: aportaciones para el debate en España». Revista Española de Derecho Constitucional, 108, 123-153.doi: http://dx.doi.org/10.18042/cepc/ redc.108.04. Por su parte, CASTellá Andreu, J. M. (2016), «El referéndum en la Constitución: ¿es necesario un replanteamiento de la institución?», en Cascajo Castro, J. L. y Martín de LA Vega, A. (coords.), Participación, representación y democracia. XII Congreso de la Asociación de Constitucionalistas de España. Valencia, Tirant lo Blanch, p. 253 ss., intenta una ordenación de algunos de los principales modelos comparados, en función de la mayor o menor importancia que dan al referéndum. En el extremo mínimo estarían, a nivel federal, Alemania y Estados Unidos, que no prevén ningún tipo de referéndum en este ámbito (aunque como es sabido, en Estados Unidos son muy frecuentes los referéndums a nivel estatal). En el otro extremo estaría Suiza, en el que las instituciones de democracia directa tienen un gran peso. Entre medias, y de menos a más, estarían Japón (solo previsto para la reforma constitucional y todavía inédito), Canadá (tres desde la creación de la Federación en 1867), Reino Unido, Francia, e Italia, con su previsión de referéndum abrogatorio. Este interesante trabajo insiste también en dos elementos relevantes: la valoración de un sistema no puede hacerse solo basándose en su regulación constitucional y legal, sino que ha de considerarse su práctica. Y, por otro lado, es importante una perspectiva dinámica que tenga en cuenta la evolución de los sistemas, y de acuerdo con la cual, la tendencia es a una cada vez más frecuente utilización de este instrumento.

En cuanto a trabajos monográficos sobre algunos de los más significativos sistemas más próximos al nuestro, en materia de referéndum (además de las referencias contenidas en la bibliografía que citaremos respecto al sistema español), cabe mencionar Pérez Sola, N. (2008), «La institución del referéndum en Francia tras la reforma constitucional: una perspectiva comparada», en Cuadernos de Derecho Público, n. ${ }^{\circ} 34-35$; del mismo autor, (1992), «Breve análisis de las experiencias de referéndum en la V República francesa», en Revista de Estudios Políticos, n. ${ }^{\circ} 78$, p. 331 ss.; y (1993), «El referéndum abrogativo italiano: evolución jurisprudencial y efectos políticos», en Cuadernos Constitucionales de la Cátedra Fadrique Furió Ceriol, n. ${ }^{\circ} 4$, pp. 51 ss.

Del estudio de estos dos sistemas, con una regulación mucho más abierta que la española, y una práctica más abundante, se deduce que esta institución ofrece claras ventajas desde el punto de vista de las posibilidades de participación ciudadana directa, pero también tiene riesgos, desde la perspectiva de su posible instrumentalización, como forma de bloqueo o presión al parlamento representante del pueblo, 
su utilización en contextos no democráticos, o de poca calidad democrática, ha permitido a veces su manipulación, o simplemente el abuso tendente a la mera legitimación de un poder que en realidad carece de ella ${ }^{6}$. Por este motivo, entre otros, ha existido tradicionalmente un debate sobre la conveniencia de una mayor o menor implantación y utilización de este instrumento. Más recientemente, y al hilo de algunas consultas populares de resultado inesperado en algunos países, el debate se ha centrado en las condiciones adecuadas para que el referéndum pueda cumplir su función de instrumento para la participación ciudadana y mejora de la calidad democrática, para lo cual será muy importante valorar diversas circunstancias políticas y sociales, así como la posibilidad real de un debate abierto sobre el tema ${ }^{7}$. Desde luego, también se plantea la idoneidad del referéndum como instrumento para el

por parte de quien puede instarlo (este tipo de problemas se han dado tanto cuando la convocatoria corresponde a jefe del Estado, como cuando procede de iniciativa popular). También cabe apreciar las diferencias muy significativas en cuanto al nivel de participación, incluso en el mismo país (caso de Italia) en función de las circunstancias del momento.

En cambio, quizá cabría extraer otras conclusiones del análisis del caso suizo. Como apunta el ya mencionado trabajo de SÁENZ Royo, E. (2016), «Regulación y práctica del referéndum en Suiza...», ob. cit., pp. 99 ss., «las grandes críticas vertidas sobre la institución de referéndum son más bien problemas referidos a la práctica del referéndum en las democracias actuales y no tanto problemas de principio». En este sentido, el uso del referéndum en Suiza no parece haber materializado ninguna de las objeciones que habitualmente se hacen a este instrumento: ni ha supuesto un choque de legitimidades entre el pueblo y el Parlamento, ni ha servido para la consolidación de las mayorías y la desprotección de las minorías, ni ha sido un instrumento susceptible de utilización manipulada en manos de las élites, ya que su iniciativa corresponde a los propios ciudadanos. Eso sí, de acuerdo con la misma autora (p. 101), dos son los precios que ha tenido que pagar Suiza por la utilización saludable y positiva de esta institución: «Por una parte, los largos procesos para la toma de decisiones. Por otra parte, la escasa participación en la mayoría de las consultas».

${ }^{6}$ Véase en esta línea, por ejemplo, Espín Templado, E. (1994), Lecciones de Derecho Político, Valencia, Tirant Lo Blanch, p. 58. Por su parte, Welp, Y. (2010), «El referendo en América latina. Diseños institucionales y equilibrios de poder», en Nueva Sociedad, n. ${ }^{\circ} 228$, marzo-agosto, p. 27 , menciona que «durante el siglo xx, varios países convocaron referendos, tanto durante gobiernos autoritarios (Bolivia 1931; Paraguay 1940; Chile 1978, 1980; Uruguay 1980), como en democracias con dudosas credenciales (Perú 1919, Uruguay 1942), en democracias frágiles (Brasil 1963) y en democracias consolidadas o en consolidación (Uruguay en numerosas ocasiones)». Y más adelante, en pág. 30, señala ejemplos europeos: «más de un líder autoritario - Napoleón III (1870), Adolf Hitlen $(1933,1934,1935,1936$ y 1938) y Francisco Franco $(1947,1966)$ - recurrió al referendo para consolidar su poder o movilizar a las masas». En su opinión, la diferencia entre estos casos y los ejemplos de referéndums en contextos claramente democráticos, como Suiza o Estados Unidos, «pasa por quien puede iniciar la consulta ciudadana. Mientras que en Suiza solo la ciudadanía y la Constitución están habilitadas para dar inicio a un referendo (el Parlamento puede presentar contrapropuestas cuando se trata de iniciativas constitucionales), en los otros casos citados el poder radica exclusivamente en el Ejecutivo».

7 Sobre la cuestión es muy recomendable el artículo de GARGARELLA, R. (2017), «Reivindicación de los plebiscitos», en El País, 10 de febrero de 2017 (consulta en web, https:/elpais.com/ elpais/2017/02/09/opinion/1486644995_314713.html, fecha de última consulta 10 de enero de 2018), quien analiza algunas de las circunstancias apuntadas. 
ejercicio del derecho de libre determinación de los pueblos, o de un supuesto «derecho a decidir» ${ }^{8}$.

En cualquier caso, y sin que podamos profundizar en este debate, lo cierto es que la regulación que un concreto sistema haga de este instrumento constituye un buen «termómetro» para reflejar la confianza que se tiene en los beneficios de su uso, como instrumento de participación ciudadana directa. Si ello es así, parece que el entusiasmo del constituyente de 1978 por el referéndum fue más bien bajo. Por un lado, se prevén los referéndums para la reforma constitucional (arts. 167 y 167 de la Constitución), entre los cuales solo el de la vía agravada (art. 168) es preceptivo9. Ello ha permitido, como es sabido, que las únicas dos ocasiones en las que se ha reformado la Constitución, en 1992 y en 2011, no se haya llevado a cabo un referéndum, dado que no lo solicitaron un mínimo del diez por cierto de los miembros en ninguna de las dos cámaras.

${ }^{8}$ Hay, incluso en nuestra doctrina, bibliografía sobre esta cuestión, en particular sobre los casos de Escocia y Quebec, y en la que no podemos profundizar. Cabe citar el libro de Tornos MAs, J. (2015), De Escocia a Cataluña. Referéndum y reforma constitucional, Madrid, Iustel. Más recientemente, el Tribunal Constitucional Federal alemán, en sentencia n. ${ }^{\circ} 118$, de 29 de abril de 2015 , ha rechazado que un Land pueda celebrar un referéndum de independencia. Un interesante comentario sobre los diversos casos europeos puede encontrarse en el trabajo de Montilla Martos, J. A. (2016), «El referéndum de secesión en Europa». Revista de Derecho Constitucional Europeo, año 13, n. ${ }^{\circ} 26$, julio-diciembre.

En el caso español, como es sobradamente conocido, el Tribunal Constitucional ha interpretado el llamado «derecho a decidir» de conformidad con la Constitución, excluyendo que pueda implicar un referéndum de autodeterminación fuera de los cauces previstos en la norma fundamental. En efecto, la STC 42/2014, de 25 de marzo, f. j. 3, defiende que es admisible la «interpretación de que el «derecho a decidir de los ciudadanos de Cataluña» no aparece proclamado como una manifestación de un derecho a la autodeterminación no reconocido en la Constitución, o como una atribución de soberanía no reconocida en ella, sino como una aspiración política a la que solo puede llegarse mediante un proceso ajustado a la legalidad constitucional con respeto a los principios de «legitimidad democrática», «pluralismo», y «legalidad», expresamente proclamados en la Declaración en estrecha relación con el «derecho a decidir». Por cierto, un poco antes esta misma sentencia hace referencia expresa al caso de Quebec, al señalar que «en el marco de la Constitución una Comunidad Autónoma no puede unilateralmente convocar un referéndum de autodeterminación para decidir sobre su integración en España. Esta conclusión es del mismo tenor que la que formuló el Tribunal Supremo del Canadá en el pronunciamiento de 20 de agosto de 1998, en el que rechazó la adecuación de un proyecto unilateral de secesión por parte de una de sus provincias tanto a su Constitución como a los postulados del Derecho internacional».

9 Un comentario a los distintos tipos de referéndum previstos en la Constitución española puede verse por ejemplo en Aguiar de LuQue, L., (2013), «El referéndum en la Constitución española; una reflexión sobre una institución problemática», en LóPEz GUERRA, L., et alii (dirs.), Constitución y desarrollo político. Estudios en homenaje al profesor Jorge de Esteban, Valencia, Tirant Lo Blanch. Sobre el tema, véase también el trabajo de Oliver Araujo, J. (1989), «El referéndum en el sistema constitucional español», en Revista de Derecho Político, UNED, n. ${ }^{\circ}$ 29; PÉREz SolA, N. (1994), La regulación constitucional del referéndum, Universidad de Jaén; PÉrez Alberdi, M. R. (2013), El derecho fundamental a participar en los asuntos públicos, Madrid, Congreso de los Diputados; Castellá Andreu, J. M. (2016), «El referéndum...», ob. cit., pp. 235 ss. 
Por otro lado, la Constitución menciona el referéndum para la iniciativa autonómica, solo en el caso de que esta se hubiera llevado a cabo por la llamada «vía agravada» (art. 151.1) en territorios que no hubieran plebiscitado históricamente proyectos de Estatuto de autonomía (Disposición Transitoria Segunda), situación que en la práctica únicamente se dio en Andalucía. En el mismo artículo 151, en su apartado $2,3 .^{\circ}$ y $5 .^{\circ}$, la Constitución recoge el referéndum de aprobación del Estatuto, que solo fue necesario en aquellos que siguieron esta vía (Cataluña, País Vasco, Galicia y la propia Andalucía). Por su parte, la reforma de los Estatutos aprobados por esta vía requerirá en todo caso referéndum (art. 152.2), mientras que en los demás supuestos, solo procederá referéndum si así lo prevé el propio texto estatutario, como cabe deducir del artículo 147.3, que ni lo impone ni lo excluye.

Fuera de los casos mencionados, que en cierta medida pueden considerarse excepcionales, la Constitución solo prevé la posibilidad de llevar a cabo un referéndum consultivo (art. 92) para «decisiones políticas de especial trascendencia». Como es sabido, su convocatoria corresponde al rey a propuesta del presidente del Gobierno (que es obviamente quien adopta la decisión), y ha de ser previamente autorizada por el Congreso de los Diputados (art. 92.2). Por último, el art. 149.1. 32. ${ }^{a}$ establece como competencia exclusiva del Estado la «autorización para la convocatoria de consultas populares por vía de referéndum».

Creo que lo anterior muestra una regulación ciertamente restrictiva del referéndum. Esta restricción, al menos para el supuesto más general del artículo 92, se manifiesta en el proceso constituyente, ya que una enmienda «in voce» modificó sustancialmente el texto del informe de la Ponencia (art. 85), que preveía la posibilidad de referéndum para «las leyes aprobadas por las Cortes y aún no sancionadas, las decisiones políticas de especial trascendencia, y la derogación de las leyes en vigor»; además el referéndum sobre decisiones políticas no se plasmaba como consultivo, y el texto era más flexible en lo relativo a la iniciativa, ya que con carácter general podía proceder del Gobierno, «a iniciativa propia o de cualquiera de las Cámaras», pero además el referéndum derogatorio podría ser propuesto por tres Comunidades Autónomas o 750.000 electores. Los debates en la Comisión del Congreso confirman que la sustitución por la redacción vigente, más restrictiva, pareció tener como fundamento el intento de evitar el menoscabo o merma de la posición del Parlamento ${ }^{10}$. En todo caso, lo que parece indudable es que la opción finalmen-

10 Véase Diario de Sesiones del Congreso de los Diputados, Comisión de Asuntos Constitucionales y Libertades Públicas, año 1978, número 81, 16 de junio de 1978, pp. 2936 ss. (disponible en web http://www. congreso.es/est_consti/ ). Fraga Iribarne, defendiendo el texto más amplio de la Ponencia, entendió que las instituciones de participación directa eran «una compensación necesaria, de raíz profundamente populista y de raíz profundamente democrática» (p. 2936). En cambio, Solé Tura defendió la enmienda in voce cuestionando los tres tipos de referéndum, aunque admitiendo que el relativo a decisiones políticas podría ser consultivo. En cuanto al referéndum legislativo, señaló que «abre una extraña posibilidad de que la soberanía del Parlamento sea absolutamente menoscabada y establece, sobre todo, la posibilidad de conflictos muy serios entre Gobierno, Rey y Parlamento, puesto que se trata de leyes que ya han sido aprobadas pero que antes de ser sancionadas pueden ser sometidas a referéndum a propuesta del Gobierno, etc., tal como 
te adoptada por el constituyente fue consciente y se basaba en la opción por un modelo de democracia representativa en el que el papel del referéndum resultaba claramente secundario ${ }^{11}$.

En suma, en su redacción que finalmente fue aprobada, el referéndum del artículo 92 solo cabe con carácter consultivo y para decisiones políticas (es decir, lo que suele llamarse plebiscito), pero no parece contemplarse respecto a normas ${ }^{12}$, ni tampoco como referéndum derogatorio o abrogatorio. Por otro lado, parece que solo podría plantearse en todo el territorio nacional ${ }^{13}$. Cualquier otro referéndum (por ejemplo, de ámbito autonómico o local) conllevaría la autorización por parte del Estado.

dice aquí, en cuyo caso, prácticamente, toda decisión de las Cámaras queda menoscabada»; en cuanto al referéndum sobre decisiones políticas, justificó que solo debía mantenerse como consultivo señalando que «si no se matiza, puede dar lugar también a que el Parlamento quede absolutamente colocado en un segundo plano y, desde luego, establecemos una dinámica que puede prácticamente, no sólo establecer grandes conflictos entre los diversos poderes, sino reducir también al Parlamento a un papel absolutamente mínimo» (p. 2937); respecto al referéndum derogatorio, consideró preferible que no se contemplase. En su respuesta, Fraga cuestionó el invocado principio de soberanía del Parlamento, que no existe como tal en el texto constitucional, ya que este se refiere a «la soberanía nacional que reside en el pueblo español, del que emanan todos los poderes del Estado, incluyendo, naturalmente, al Parlamento»; y achaca a Solé Tura «una posición aristocrática del Parlamento», más propia de siglos anteriores, añadiendo que solo él, en la ponencia, «como conservador reformista, era el único que defendía seriamente la iniciativa popular y veo que, efectivamente, soy el único que la sigue defendiendo» (pp. 2938-2939). José Pedro PéreZ-LlorCa se sumó a la enmienda de SOLÉ TURA, argumentando que el referéndum sobre las leyes podía convertirse en una especie de «veto plebiscitario»; y en cuanto al referéndum derogatorio, consideró que "para el armónico desarrollo, el armónico crecimiento del sistema constitucional a través del conjunto de leyes orgánicas, que por mayoría absoluta del Congreso deberán ser aprobadas, tarea esta legislativa ciertamente que excederá más de un lustro, no conviene en este momento introducir tampoco la técnica del referéndum derogatorio o abrogatorio» (p. 2940). Ciertamente, cabe apuntar que aunque se suscribiera este argumento... habría perdido toda su virtualidad cuatro décadas después.

Por su parte, Alzaga Villamil, O. (2016), Comentario sistemático a la Constitución española de 1978, Madrid, Marcial Pons, 2. ${ }^{a}$ edición, p. 447, comentando este proceso, entiende que la causa del abandono del referéndum derogatorio fue que la inmensa mayoría de las fuerzas políticas estimaron como negativa la experiencia italiana del referéndum abrogatorio, que «ha generado no pocos problemas y enturbiado un poco el ambiente político, facilitando un campo de juego idóneo a los partidos políticos marginales y extraparlamentarios...»

${ }^{11}$ Véase, en esta línea, Castellá Andreu, J. M. (2016), ob. cit., p. 241, que afirma que «la opción del constituyente respondía también a razones de fondo, de modelo de democracia, a la relación entre representación y participación directa en el contexto de la soberanía popular, y por tanto con pretensiones de continuidad en el tiempo».

12 Aunque el artículo 3 de la Ley Orgánica reguladora de las distintas modalidades de Referéndum (LODMR) se refiere a que el Real Decreto de convocatoria «contendrá el texto íntegro del proyecto de disposición o, en su caso, de la decisión política objeto de la consulta», no hay que olvidar que este precepto trata de regular todas las modalidades de referéndum, incluyendo por tanto las que suponen un pronunciamiento de un texto, como son los de reforma constitucional o aprobación o reforma de ciertos Estatutos.

${ }^{13}$ De nuevo, el artículo 5 LODMR al proclamar que el referéndum «se decidirá por sufragio universal, libre, igual, directo y secreto en el ámbito que corresponda a la consulta» está incluyendo los referéndums estatutarios, cuyo ámbito territorial es lógicamente más reducido. 
Por su parte, la Ley Orgánica 2/1980, de 18 de enero, reguladora de las distintas modalidades de Referéndum, si bien contiene diversos preceptos generales, y algunos relativos al procedimiento, como es evidente no tiene margen para flexibilizar o ampliar los supuestos constitucionalmente tasados, ni suprimir o rebajar las restricciones constitucionales.

El Tribunal Constitucional, que ha tenido ocasión de pronunciarse en varias ocasiones sobre algunas modalidades de referéndum, ha mantenido la visión restrictiva, estableciendo que no es posible decidir mediante referéndum cuestiones que quedan reservadas por la propia Constitución al pueblo soberano, y por tanto solo podrían adoptarse mediante la reforma constitucional ${ }^{14}$, o que las Comunidades Autónomas no pueden convocar referéndums no autorizados por el Estado, ni siquiera por la vía de tratar de convertirlos en «consultas» no sometidas a ese régimen ${ }^{15}$.

14 STC 103/2008, de 11 de septiembre, f. j. 4: «La cuestión que ha querido someterse a consulta de los ciudadanos de la Comunidad Autónoma del País Vasco afecta (art. 2 CE) al fundamento del orden constitucional vigente (en la medida en que supone la reconsideración de la identidad y unidad del sujeto soberano o, cuando menos, de la relación que únicamente la voluntad de éste puede establecer entre el Estado y las Comunidades Autónomas) y por ello sólo puede ser objeto de consulta popular por vía del referéndum de revisión constitucional. Es un asunto reservado en su tratamiento institucional al procedimiento del art. $168 \mathrm{CE}$. La que aquí nos ocupa no puede ser planteada como cuestión sobre la que simplemente se interesa el parecer no vinculante del cuerpo electoral del País Vasco, puesto que con ella se incide sobre cuestiones fundamentales resueltas con el proceso constituyente y que resultan sustraídas a la decisión de los poderes constituidos» En la misma línea, pueden verse las SSTC 31/2010, de 28 de junio, f.j. 69; 31/2015 y 32/2015, ambas de 25 de febrero; 51/2017, de 10 de mayo.

15 Véase la propia STC 103/2008, de 11 de septiembre, f. j. 2: «El referéndum es, por tanto, una especie del género «consulta popular» con la que no se recaba la opinión de cualquier colectivo sobre cualesquiera asuntos de interés público a través de cualesquiera procedimientos, sino aquella consulta cuyo objeto se refiere estrictamente al parecer del cuerpo electoral (expresivo de la voluntad del pueblo: STC 12/2008, de 29 de enero, FJ 10) conformado y exteriorizado a través de un procedimiento electoral, esto es, basado en el censo, gestionado por la Administración electoral y asegurado con garantías jurisdiccionales específicas (...). Para calificar una consulta como referéndum o, más precisamente, para determinar si una consulta popular se verifica «por vía de referéndum» (art. 149.1.32 CE) y su convocatoria requiere entonces de una autorización reservada al Estado, ha de atenderse a la identidad del sujeto consultado, de manera que siempre que éste sea el cuerpo electoral, cuya vía de manifestación propia es la de los distintos procedimientos electorales, con sus correspondientes garantías, estaremos ante una consulta referendaria». También puede añadirse la cita ya transcrita de la STC 42/2014, de 25 de marzo, f. j. 3, específicamente referida a la imposibilidad constitucional de un referéndum de autodeterminación llevado a cabo por una Comunidad Autónoma. Y, más recientemente, la STC 114/2017, de 17 de octubre, que declaró inconstitucional la Ley del Parlamento de Cataluña 19/2017, de 6 de septiembre, denominada «del referéndum de autodeterminación», recapitula la jurisprudencia esencial en la materia, señalando que «si bien la previsión por el constituyente de unos concretos supuestos de referéndum no agota el elenco de otros admisibles en nuestro ordenamiento, solo a la ley orgánica a la que remite el citado artículo 92.3 CE correspondería la previsión genérica o en abstracto de tales consultas referendarias distintas a las contempladas de modo expreso en la norma fundamental», y añade que «no pueden someterse a consulta popular autonómi$\mathrm{ca}$ - referendaria o no- cuestiones fundamentales que fueron resueltas en el proceso constituyente y que están sustraídas a la decisión de los poderes constituidos [STC 51/2017, FJ 5 c) y d), con cita de pronunciamientos anteriores]». 
De este modo, la competencia estatal abarca no solo la autorización de consultas populares por vía de referéndum, sino también el establecimiento y regulación del referéndum, sea cual sea su modalidad y ámbito territorial, si bien las Comunidades Autónomas pueden asumir competencias en materia de ejecución, o incluso en el «complemento normativo» a la regulación estatal, pero siempre dentro de su ámbito de competencias ${ }^{16}$.

Desde luego, la jurisprudencia constitucional que considera que no pueden someterse a un referéndum (distinto al de la reforma constitucional) los aspectos que afectan a la definición del sujeto de la soberanía, o que las Comunidades Autónomas no podrían celebrar referéndums sobre cuestiones que quedan fuera de su ámbito competencial, introduce criterios equiparables a los que existen en la mayoría de los Estados descentralizados. Y, por lo demás, es la propia Constitución, como vengo apuntando, la que ha llevado a cabo una regulación restrictiva del referéndum. Pero acaso la propia jurisprudencia constitucional ha profundizado en esa línea restrictiva, limitando bastante las posibles intervenciones de las Comunidades Autónomas en la regulación y ejecución de todo tipo de consultas, probablemente más que en la mayoría de los Estados descentralizados, como de alguna manera viene a reconocer el propio Tribunal ${ }^{17}$.

16 Por todas, STC 51/2017, de 10 de mayo, f. j. 5. Señala el Tribunal expresamente que «el Estado tiene competencia exclusiva para el «establecimiento y regulación» del referéndum, ello en atención a que este instituto es cauce para la participación directa de los ciudadanos en los asuntos públicos, participación de carácter político que es objeto de un derecho fundamental (art. 23.1 CE) cuyo desarrollo corresponde solo a la ley orgánica (art. 81.1 CE) y, más específicamente, a la prevista en el artículo 92.3 CE para la regulación de las «condiciones y el procedimiento de las distintas modalidades de referéndum previstas en esta Constitución». Con arreglo a las citadas normas constitucionales, en suma, el Estado es competente para regular la institución del referéndum «cualquiera que sea la modalidad o ámbito territorial sobre el que se proyecte» [STC 31/2015, FJ 6 A)], ello sin perjuicio, cabe ya observar, de las salvedades también presentes en nuestra jurisprudencia», que en definitiva se resumen en las que precisó la STC 137/2015, de 11 de junio, en el sentido de que «en el respeto a esta exclusiva competencia del Estado y a las normas de la Constitución en su conjunto», los estatutos de autonomía podían «reconocer a las Comunidades Autónomas algún género de intervención en la ejecución o, incluso, en el complemento normativo de los preceptos estatales que disciplinen, en los términos señalados, unas u otras figuras de referéndum, siempre que ello se realizara, claro está, sobre asuntos de competencia de la respectiva Comunidad Autónoma» (FJ 4).

En suma, la jurisprudencia constitucional en la materia ha incidido en la línea restrictiva del referéndum en el ámbito autonómico. Véanse en esta línea (aunque obviamente no comprenden las sentencias más recientes) los análisis de Aguado Renedo, C. (2011), «Referéndum autonómico y jurisprudencia constitucional», en Teoría y realidad constitucional, n. ${ }^{\circ} 28$, pp. 541 ss., o Castellá Andreu, J. M., «El referéndum», op. cit., p. 250.

${ }^{17}$ La STC 51/2017, de 10 de mayo, f. j. 4, ofrece el siguiente repaso de la cuestión: «En los Estados federales se reconoce por lo general la competencia de las entidades federadas para regular y establecer sus modalidades referendarias. Suiza destaca sin duda como el Estado de nuestro entorno en el que el referéndum se regula y se practica con mayor amplitud, en todos sus niveles territoriales (federal, cantonal y local): en dicho Estado los referéndums de ámbito cantonal se regulan en la Constitución de cada cantón, y tienen carácter vinculante o consultivo. En Alemania, aunque 
Además de estas restricciones constitucionales, nos encontramos con que la práctica de los referéndums ha sido bastante escasa. Las dos veces que se ha reformado la Constitución se ha hecho por la vía ordinaria y sin referéndum. En cuanto a los Estatutos, solo en los casos ya mencionados fue necesario el referéndum de aprobación, y el de reforma ha sido celebrado en Cataluña y Andalucía ${ }^{18}$. Por su parte, en cuatro décadas solo se han convocado dos referéndums consultivos de los previstos en el artículo 92: el referéndum sobre permanencia en la OTAN en 1986, y el relativo a la Constitución europea en 2005. En algunas ocasiones se han autorizado también referéndums municipales.

En todo caso, como se ve, la utilización de este instrumento ha sido poco frecuente. Aun así, en las ocasiones en las que se ha celebrado, la participación ha sido en general reducida, y desde luego bastante por debajo de la habitual en otros procesos electorales, lo cual no solo se ha producido en los casos de referéndums consultivos, sino también en los necesarios para aprobación y reforma de los Estatutos.

En este contexto, a veces se han realizado críticas a esta regulación restrictiva, o se han realizado propuestas para ampliar las posibilidades de uso de este instrumento. En esta línea, se sugiere a veces la necesidad de que el referéndum fuera preceptivo en todos los casos de reforma constitucional, así como reformas que permitieran referéndums vinculantes en ciertas hipótesis, u otros que tuvieran un ámbito territorial inferior al nacional.

la institución del referéndum tiene carácter excepcional en el nivel federal (cfr. art. 29 de la Ley Fundamental de Bonn), las constituciones de algunos Länder regulan ciertas modalidades de consulta popular, incluidas las referendarias, para la modificación de la Constitución del Land, la aprobación de leyes u otras cuestiones. Igualmente, las constituciones de los Länder austriacos prevén modalidades de consulta.

En lo que se refiere, por otro lado, a los Estados regionales de nuestro entorno, destaca a este respecto la Constitución italiana, que contempla expresamente la competencia de los estatutos regionales para regular el referéndum y establecer su naturaleza y objeto, como parte de la configuración de las reglas básicas de la región (art. 123). Con base en esta previsión constitucional, el Tribunal Constitucional italiano considera que la materia referendaria pertenece a los contenidos obligatorios del Estatuto, y que a las regiones se les permite articular la ordenación de los referéndums regionales de forma diferente a la tipología de referéndums previstos en la Constitución, incluso innovando con ellos en varios aspectos, precisamente porque cada región es libre de diseñar formas, métodos y criterios de participación popular en el proceso de control democrático de los actos regionales (Sentencia núm. 372, de 29 de noviembre de 2004, apartado 8)».

Aunque desde luego, como añade de inmediato el Tribunal «Nota común al régimen jurídicoconstitucional de las modalidades de referéndum de ámbito infraestatal que se reconocen en los ordenamientos de nuestro entorno es la de que deben tener siempre como objeto, incluso aunque revistan naturaleza consultiva, materias o asuntos de la competencia del Land o región correspondiente, de tal forma que sus efectos se proyecten solo sobre el ámbito del Land o región y sus instituciones».

${ }_{18}$ Pueden verse los datos en http://www.juntaelectoralcentral.es/cs/jec/referendos/autonomicos (fecha de consulta 9-10-2017) 
Es difícil valorar la conveniencia real de estas medidas, así como la posibilidad de que su implantación condujera realmente a una mayor utilización del referéndum por los poderes públicos, y una mayor participación ciudadana en estos procesos. En mi opinión, desde luego la posibilidad de reforma constitucional sin referéndum, en asuntos que no tengan especial trascendencia, o en aquellos en los que el consenso sobre los aspectos a reformar es muy elevado, no parece negativa, y además es acorde con lo que sucede en la mayoría de los países de nuestro entorno. Las propias experiencias de las dos reformas, y en especial la de 1992, ponen de relieve que su aprobación por unas mayorías elevadísimas en ambas cámaras permitía deducir razonablemente un apoyo suficiente por parte de los ciudadanos representados por las fuerzas políticas que apoyaron la reforma, y además se posibilitó una reforma más ágil y menos costosa. Es verdad que en 2011 se produjeron críticas al procedimiento de urgencia mediante el que se aprobó la reforma, y también lo es que algunos invocaron la conveniencia de llevar a cabo un referéndum, pero el mero hecho de que las fuerzas que lo pedían no alcanzasen siquiera el $10 \%$ de los diputados o senadores (en cuyo caso, como es sabido, tendría que haberse celebrado el referéndum en todo caso) pone de relieve el bajo apoyo que tuvo la idea de la necesidad de un referéndum. Aunque últimamente hemos encontrado en el mundo varios casos de referéndums en los que la propuesta del poder político convocante es rechazada, no parece imaginable esta situación si dicha propuesta tiene una ratificación superior al noventa por ciento de los representantes en ambas cámaras.

Más sentido pueden tener las restantes críticas, que nos hacen pensar seriamente en la conveniencia de ampliar los posibles supuestos de referéndum en una futura reforma constitucional. No se aprecia con claridad el fundamento de impedir referéndums vinculantes, o referéndums sobre proyectos legales de especial trascendencia, en casos en los que se estime conveniente. Por otro lado, y además del mencionado supuesto de autorización del art. 149.1. 32. ${ }^{\mathrm{a}}$, tampoco creo que resulte necesario impedir la opción de un referéndum convocado en un ámbito territorial determinado. Sobre este aspecto, la doctrina ha debatido si con la redacción actual ello sería posible. Todo ello para considerar la eventualidad de un posible referéndum en una Comunidad Autónoma o territorio determinado, en el que se preguntase sobre la independencia de ese territorio. Aunque hay opiniones en uno u otro sentido, parece que la referencia del artículo 92.1 a «todos los ciudadanos» apunta a que el referéndum debe llevarse a cabo en todo el territorio nacional, sin perjuicio la posibilidad de que se «autoricen» otros de ámbito territorial inferior. En todo caso, hay que considerar que un referéndum de este tipo solo podría ser consultivo, pues de lo contrario supondría una usurpación de la soberanía nacional, que según el artículo 1.2 recae en todo el pueblo español, por una parte de la población. Con todo, una fórmula de este tipo, rodeada de las garantías necesarias y de una regulación muy clara del procedimiento y pasos a seguir, podría abrir la puerta a una solución «al estilo Quebec» a supuestos como el de Cataluña. El problema es que según la redacción actual del artículo 92 (y de acuerdo también con la jurispruden- 
cia constitucional hasta ahora existente, sintéticamente descrita un poco más arriba) eso no parece posible, con lo cual sería necesaria una reforma de este artículo, un posterior referéndum, y en caso de que la respuesta a este fuese afirmativa, una nueva reforma constitucional, que requeriría la ratificación de todo el pueblo español, que probablemente no se pronunciase en el mismo sentido. Así que no parece que esta sea la solución ni la salida a la situación existente. En todo caso, esta cuestión excede del objeto de análisis de este trabajo, en el cual solo hemos pretendido justificar que podría resultar positivo, no necesariamente para casos de este tipo, la posibilidad de celebrar referéndums en un ámbito territorial menor que el del Estado ${ }^{19}$.

\subsection{La iniciativa legislativa popular}

La iniciativa legislativa popular es un instrumento de democracia semidirecta, en la medida en que permite a los ciudadanos participar en el proceso de adopción de decisiones (en este caso, de elaboración de una ley), aunque no queda en sus manos la decisión final adoptada. En todo caso, es un instrumento importante de participación ciudadana, que viene a complementar a la democracia representativa, permitiendo al parlamento posicionarse sobre cuestiones que tengan interés para la sociedad o reflejen demandas sociales, que sin embargo, por las razones que sean, no hayan tenido reflejo en la actividad legislativa de la asamblea. Ciertamente, ello implica que el ejercicio de la iniciativa legislativa popular suele poner de relieve una cierta deficiencia de la actuación parlamentaria, o una falta de conexión entre representantes y representados. En efecto, teniendo los grupos parlamentarios iniciativa legislativa, y representando estos en principio el pluralismo político de una sociedad, el hecho de que ninguno de los parlamentarios haya propuesto algo, y que hayan tenido que ser los propios ciudadanos quienes se movilicen para formular la propuesta, puede significar que no ha habido suficiente sintonía, o que al menos un sector de la población no ha encontrado reflejo en sus representantes. Es verdad que a veces estas iniciativas pueden obedecer a otros motivos (es posible, por ejemplo, que grupos parlamentarios minoritarios prefieran acudir a la movilización social para dar más fuerza a determinadas iniciativas, o bien representantes que no alcanzan los umbrales mínimos para presentar una iniciativa de este tipo busquen apoyo a sus propuestas a través de los ciudadanos), pero en cualquier caso suelen ser una manifestación de supuestos en los que los canales normales del sistema representativo no han sido suficientes. Aunque, por esta misma razón, puede decirse que la iniciativa legislativa popular es un complemento necesario en todo modelo de democracia representativa.

${ }^{19}$ Una investigación del mayor interés sobre el concepto de ciudadanía, y entre otros aspectos, sus relaciones con el de soberanía, en Coello Garcés, C. (2016), Repensar la ciudadanía. Derechos políticos de las minorías y grupos vulnerables, Ciudad de México, Tirant Lo Blanch. 
Como en los demás casos, lejos de llevar a cabo un análisis completo de la regulación constitucional y legal de esta materia ${ }^{20}$, me centraré en señalar los aspectos que, a mi juicio, ponen de relieve que esta regulación tiende a una restricción excesiva de esta forma de participación ciudadana. Estos son, a mi juicio, los siguientes:

a) El número de firmas exigido parece elevado, si lo enmarcamos en el ámbito comparado (siempre suele mencionarse como ejemplo mucho más abierto el de Italia, donde con una población superior a la española, la Constitución exige en su artículo 71 una cifra de 50.000 firmas, un diez por ciento de la que pide nuestra Constitución ${ }^{21}$ ).

b) No queda muy claro qué finalidad persigue o qué beneficios puede conseguir la prohibición de iniciativa legislativa para la reforma constitucional, derivada del artículo 166 en relación con el 87 de la Constitución. En una situación en la que parece abrirse paso, desde hace bastantes años, la alta conveniencia de una reforma constitucional, que sin embargo no logra dar sus primeros pasos por falta de iniciativa política, tal vez una iniciativa popular pudiera suponer el punto de partida que no se termina de dar, o el empuje necesario para tomarse en serio esta tarea pendiente, cada vez más perentoria.

c) La abundancia de las materias que están vedadas a la iniciativa popular. Ya el artículo 87.3 impide el ejercicio de esta iniciativa en «materias propias de ley orgánica, tributarias o de carácter internacional», así como en lo relativo a la prerrogativa de gracia. Por su parte, la LORIP, además de reiterar estas materias, incorpora otras. Ciertamente, no se trata de materias que el propio legislador haya decidido añadir a las prohibiciones de la norma fundamental (en cuyo caso podrían plantearse problemas de constitucionalidad, si la restricción del derecho fundamental careciera de justificación), sino de limitaciones que derivan de otros preceptos constitucionales que reservan al Gobierno determinadas iniciativas (así, el art. 131 que reserva al Gobierno los proyectos de planificación económica, y el 134.1, que establece idéntica reserva para la elaboración de los presupuestos generales del Estado, preceptos a los que se remite expresamente el artículo 2 LORIP). Además, el

20 Regulación contenida en este caso en los arts. 87.3 y 166 CE, y en la Ley Orgánica 3/1984, de 26 de marzo, reguladora de la iniciativa legislativa popular (LORIP), reformada en varios aspectos por la LO 4/2006, de 26 de mayo, y más puntualmente por la L.O. 3/2015, de 30 de marzo, de control de la actividad económico-financiera de los Partidos Políticos. Entre la bibliografía sobre el tema, cabe destacar Fernández Ferrero, M. A. (2001), La iniciativa legislativa popular. Madrid, Centro de Estudios Políticos y Constitucionales; Cabello Fernández, M.D. (2017), Democracia directa e iniciativa legislativa popular, Valencia: Tirant lo Blanch; Cuesta López, V. (2008), Participación directa e iniciativa legislativa del ciudadano en democracia constitucional, Cizur Menor, Thomson Civitas; Biglino Campos, P. (1987), «La iniciativa legislativa popular en el ordenamiento jurídico estatal», en Revista Española de Derecho Constitucional, n. ${ }^{\circ} 19$, p. 75 ss.; PÉrez Alberdi, M. R., «El derecho fundamental...», op. cit., pp. 305 ss.

21 Véase Fernández Ferrero, M. A. (2001), La iniciativa legislativa..., op. cit., pp. 157 ss. El mismo autor realiza un amplio análisis comparado de la institución. 
art. 5.2 de la LORIP establece como causas de inadmisión, además de las relativas a que la proposición verse sobre materias vedadas, o que la iniciativa no respete los requisitos formales del artículo 3, otras que pueden tener una incidencia en el contenido o estructura de la proposición, como «el hecho de que el texto de la Proposición verse sobre materias manifiestamente distintas y carentes de homogeneidad entre sí» (apartado c); «la previa existencia en el Congreso o el Senado de un proyecto o proposición de Ley que verse sobre el mismo objeto de la iniciativa popular y que esté, cuando ésta se presenta, en el trámite de enmiendas u otro más avanzado» (apartado d); o «El hecho de que sea reproducción de otra iniciativa popular de contenido igual o sustancialmente equivalente presentada durante la legislatura en curso» (apartado e). Si bien las dos primeras causas de inadmisión tienen una fundamentación lógica, tratando de exigir unos mínimos requisitos de coherencia y sistemática, la última implica una restricción basada en un criterio meramente temporal, que si bien puede obedecer a la idea de impedir los abusos o la utilización excesivamente reiterada de este tipo de iniciativas, no deja de suponer una limitación adicional al ejercicio de este derecho.

En suma, el constituyente no puede ocultar un cierto recelo hacia este mecanismo de participación ciudadana, o al menos un cierto temor a su ejercicio abusivo o excesivo. Y el desarrollo legislativo ha mantenido el mismo espíritu restrictivo que la Constitución, añadiendo además ciertas dificultades y restricciones ${ }^{22}$.

Por si fuera poco, la utilización de este mecanismo, que comenzó siendo baja, ha ido creciendo de forma apreciable con el tiempo; en cualquier caso, el porcentaje de iniciativas de este tipo que han logrado convertirse en ley ha sido especialmente bajo ${ }^{23}$.

Con todas las cautelas, el análisis de la utilización de este mecanismo de participación pone de relieve que, si bien las restricciones constitucionales y legales se han mantenido, ello no ha impedido que el ejercicio de la iniciativa haya crecido, lo cual no parece haber supuesto que las cámaras hayan sentido un compromiso político específico a la hora de convertir en leyes esas iniciativas, ya que muy pocas de ellas han alcanzado un final aprobatorio, ni siquiera con modificaciones. Es evidente que

22 Véase en esta línea, por ejemplo, Aguiar de Luque, L. (2000), cit., p. 94.

${ }^{23}$ En febrero de 2016, la cifra era de 2 iniciativas convertidas en ley de un total de 96 presentadas. De las restantes, 37 fueron inadmitidas, y otras tantas caducaron sin alcanzar las firmas necesarias, todo ello según información de http://www.vozpopuli.com/espana/ILP-Iniciativa_popular-Congresos-Partido_Socialista_Obrero_Espanol_PSOE-Ciudadanos-Iniciativa_legislativa_popular-Congreso-PSOE_0_893310704.html (fecha de consulta 9-10-2017). En el momento de escribir estas líneas, el buscador de iniciativas del Congreso registra 137 iniciativas populares presentadas, de las cuales 15 se han presentado en lo que llevamos de la XII legislatura, 7 en la XI, 37 en la X, 23 en la IX, 13 en la VIII, 13 en la VII, 11 en la VI, 6 en la V, 7 en la IV, 2 en la III, y 3 en la II. Este mismo buscador solo ofrece una iniciativa que llegó a ser aprobada, si bien otras dos fueron subsumidas en otra diferente (fecha de consulta 9-10-2017). 
este tipo de iniciativas no implica ninguna garantía de que las Cortes Generales vayan a asumir o aprobar la propuesta de los ciudadanos, ya que estos, por elevado que sea el número de firmas conseguido, no dejan de ser una parte minoritaria de la población, mientras que las cámaras representan a todo el pueblo. Pero en todo caso cabría esperar una mayor sensibilidad hacia este tipo de propuestas que los propios representantes habían «olvidado» o de cualquier forma no habían considerado. Parece que la causa de esta situación no está (o no principalmente) en la aludida regulación restrictiva, ya que esta no ha impedido un ejercicio creciente, y finalmente significativo, de este tipo de iniciativas, de manera que las convenientes reformas en la materia, aun cuando tendieran a garantizar que el parlamento analice y considere (cuando se cumplían los requisitos formales y materiales básicos) la iniciativa, nunca podrían garantizar que esta se convirtiera en ley.

Con todo, y aunque es evidente que hay factores políticos o culturales que influyen en la descrita situación de baja incidencia de la iniciativa popular en la actividad legislativa final de las cámaras, ello no es obstáculo para destacar la conveniencia de reformar la regulación constitucional para abrir algo más este cauce de participación, e intentar que el mismo conduzca, cuando se cumplan los requisitos legales y constitucionales, al menos a una consideración y debate por parte de la cámara, permitiendo así que los ciudadanos puedan incidir de una manera positiva en la agenda legislativa del parlamento.

\subsection{El concejo abierto}

Es quizá, entre todas las instituciones de participación ciudadana recogidas en la Constitución, la que supone un ejercicio más «puro» de democracia directa. Ello porque este mecanismo permite a los vecinos adoptar directamente las decisiones que corresponden a la competencia municipal, sin la mediación de los concejales. En los municipios que siguen este sistema tradicional, el alcalde es elegido directamente por los vecinos, y no hay concejales, sino que es la propia asamblea de vecinos la que asume sus funciones. Es, por tanto, un supuesto de democracia directa en toda su extensión, ya que los vecinos participan en la iniciativa, deliberación y en la adopción de decisiones. Sin embargo, como vamos a ver, se trata de un supuesto excepcional dentro de nuestro régimen local.

La Constitución, como es sabido, se limita a una mención, señalando en su artículo 140, dentro de capítulo II del Título VIII, dedicado a la Administración local: «La ley regulará las condiciones en las que proceda el régimen de concejo abierto». El artículo 29.1 de la Ley 7/1985, de 2 de abril, reguladora de las Bases del Régimen Local (LBRL), en su redacción actual, establece los supuestos en los que procede este régimen, que son: «a) Los municipios que tradicional y voluntariamente cuenten con ese singular régimen de gobierno y administración; y b) Aquellos otros en los que por su localización geográfica, la mejor gestión de los intereses municipales u otras circunstancias lo hagan aconsejable». Por su parte, el apartado 3 del mismo precepto 
explica que en este régimen «el gobierno y la administración municipales corresponden a un Alcalde y una asamblea vecinal de la que forman parte todos los electores. Ajustan su funcionamiento a los usos, costumbres y tradiciones locales y, en su defecto, a lo establecido en esta Ley y las leyes de las Comunidades Autónomas sobre régimen local».

Por tanto, en la actualidad este régimen no se aplica en función de la población (en la regulación anterior, antes de la reforma llevada a cabo por LO 2/2011, de 28 de enero 2011, sin perjuicio de aquellos municipios que seguían ese régimen tradicionalmente, se aplicaba en todo caso para los de menos de 100 habitantes), sino de las circunstancias antes transcritas, aunque en el supuesto del apartado b) es necesaria petición de la mayoría de los vecinos, aprobación por dos tercios de los miembros del Ayuntamiento, y aprobación por la Comunidad Autónoma ${ }^{24}$.

Por su parte, el artículo 179.2 de la Ley Orgánica 5/1985, de 19 de junio, del Régimen Electoral General (LOREG) dispone que en estos municipios «los electores eligen directamente al alcalde por sistema mayoritario». Por otro lado, diversas Comunidades Autónomas han aprobado legislación específica sobre la materia.

En suma, el concejo abierto se configura hoy como un sistema de democracia directa que ha merecido la relevancia constitucional; se encuentra a mitad de camino entre el derecho consuetudinario y el derecho escrito, fuertemente enraizado en nuestra tradición local, y vigente en los municipios a los que les resulta aplicable. Su preservación debe ser un objetivo de los poderes públicos, tanto por el alto grado de participación democrática que supone, como su valor histórico y tradicional. Sin embargo, ello es compatible con su adaptación y actualización, y con las reformas que han ido abriendo un mayor margen a la voluntariedad de este régimen, toda vez que en la actualidad es probable que cada vez resulte más difícil el mantenimiento de este sistema que exige, como es obvio, una mayor dedicación de los vecinos a los asuntos públicos ${ }^{25}$. De hecho, parece que, tras la reforma legal de este régimen, en algunos lugares ha caído notoriamente el número de municipios de menos de 100 habitantes

${ }^{24}$ En la actualidad, para los municipios de menos de 100 habitantes, el art. 29.4 LBRL dispone que los alcaldes «podrán convocar a sus vecinos a Concejo Abierto para decisiones de especial trascendencia para el municipio. Si así lo hicieren deberán someterse obligatoriamente al criterio de la Asamblea vecinal constituida al efecto», y añade que «Los municipios que con anterioridad venían obligados por Ley en función del número de residentes a funcionar en Concejo Abierto, podrán continuar con ese régimen especial de gobierno y administración si tras la sesión constitutiva de la Corporación, convocada la Asamblea Vecinal, así lo acordaran por unanimidad los tres miembros electos y la mayoría de los vecinos».

${ }^{25}$ No es de extrañar que alguna legislación autonómica intente adoptar medidas para el caso de que en un municipio el régimen de concejo abierto no funcione adecuadamente: el artículo 14 de la Ley 9/2009, de 22 de diciembre, reguladora de los Concejos Abiertos en Aragón, dispone que «La falta de funcionamiento del régimen de concejo abierto, la no celebración de sesión de la Asamblea por plazo superior a seis meses y la carencia de candidatos a la Alcaldía dará lugar a la incoación de procedimiento para la fusión o incorporación del municipio a otro limítrofe o para la disolución de la entidad local menor». 
que se mantienen en el régimen de concejo abierto ${ }^{26}$. Además, la tendencia a la fusión de los municipios pequeños, como parte de un proceso de racionalización del régimen local, potenciado por la Ley 27/2013, de 27 de diciembre, de racionalización y sostenibilidad de la Administración Local, puede afectar también al número de municipios que mantengan este régimen.

En todo caso, y sin negar la importancia de este régimen y de su preservación, puede comprenderse que, desde un punto de vista del análisis global de nuestro sistema democrático, no supone una institución de gran relevancia cuantitativa.

\subsection{La participación en la Administración}

Aunque las instituciones enunciadas son las más relevantes de las que prevé la Constitución en términos estrictos de democracia directa o semidirecta, la verdad es que desde el punto de vista de la participación ciudadana en los asuntos públicos, existen otros elementos de gran importancia, como la participación en la actividad de las administraciones públicas, lo que requiere no solo la transparencia en los datos y en su actividad, sino también facilitar la posibilidad de intervenir en los procedimientos administrativos que impliquen la aprobación de normas o adopción de decisiones que les afecten.

La Constitución de 1978 no ha sido muy enfática en este punto, pero contiene al menos un artículo muy relevante, como es el 105, que remite a la ley la regulación de: «a) la audiencia de los ciudadanos, directamente o a través de las organizaciones y asociaciones reconocidas por la ley, en el procedimiento de elaboración de las disposiciones administrativas que les afecten»; «b) El acceso de los ciudadanos a los archivos y registros administrativos, salvo en lo que afecte a la seguridad y defensa del Estado, la averiguación de los delitos y la intimidad de las personas»; y «c) El procedimiento a través del cual deben producirse los actos administrativos, garantizando, cuando proceda, la audiencia del interesado».

Se incorporan así unos derechos de los ciudadanos, tanto de acceso a la información, como de participación, en este último caso tanto en la elaboración de disposiciones como en la emanación de actos administrativos. La legislación que regula la actividad de las administraciones públicas ha ido desarrollando estos derechos, siendo de destacar, en la actualidad, la Ley 39/2015, de 1 de octubre, del Procedimiento Administrativo Común de las Administraciones Públicas, cuyo artículo 13 recoge algunos derechos de las personas en sus relaciones con las administraciones; o la Ley 19/2013, de 9 de diciembre, de transparencia, acceso a la información pública y buen gobierno, no solo en lo relativo a los derechos de acceso a la información, sino también en muchos aspectos vinculados a lo que se ha dado en llamar «buen gobierno» y que

26 Véase, por ejemplo, para el caso de Castilla y León, la noticia recogida en http://www.abc.es/ espana/castilla-leon/abci-solo-29-648-municipios-menos-100-vecinos-siguen-como-concejo-abierto-201609251316_noticia.html (fecha de consulta 9-10-2017). 
de alguna manera tiene que ver con un conjunto de prácticas que incluyen exigencias de participación ciudadana, o al menos de rendición de cuentas, aspecto este que excede el ámbito de la Administración pública, para alcanzar de lleno a la comunicación entre ciudadanos y cargos públicos (no solo en el ámbito de la Administración, sino también en el de los cargos electos). También hay que mencionar, en este ámbito, una relativamente amplia y reciente legislación autonómica.

Como veremos, las exigencias ciudadanas se han elevado notoriamente en los últimos años, provocando que la regulación constitucional quede un poco obsoleta e insuficiente. Por ejemplo, el derecho de acceso a la información no aparece como derecho fundamental (aunque podría utilizarse como base el derecho a recibir información veraz del artículo 20), y los propios derechos de participación en el ámbito administrativo quedan relegados y separados del ámbito de los derechos fundamentales, mientras no hay mención alguna a derechos vinculados a la rendición de cuentas o a la comunicación entre ciudadanos y cargos públicos.

\subsection{La participación en la Administración de Justicia}

Para terminar este breve análisis de las previsiones constitucionales en materia de participación ciudadana, hay que mencionar al menos las referencias constitucionales a la participación ciudadana en la Administración de Justicia. Se trata del artículo 123, que señala: «Los ciudadanos podrán ejercer la acción popular y participar en la Administración de Justicia mediante la institución del Jurado, en la forma y con respecto a aquellos procesos penales que la ley determine, así como en los Tribunales consuetudinarios y tradicionales».

Este precepto reúne así algunas referencias a distintas instituciones participativas. Algunas de gran tradición, aunque presencia mínima, como los tribunales consuetudinarios y tradicionales (el ejemplo paradigmático es el Tribunal de las Aguas de Valencia). Otras de mucha mayor importancia, pero quizá menor tradición histórica en nuestro país, como es el Jurado, que no fue objeto de regulación hasta diecisiete años después, mediante la Ley Orgánica 5/1995, de 22 de mayo, del Tribunal del Jurado.

\section{CUATRO DÉCADAS DESPUÉS, ¿CRISIS DE CONFIANZA?}

Aunque algunas de las restricciones que el constituyente introdujo en las instituciones de democracia directa y semidirecta (y, más ampliamente, de participación ciudadana) fueron señaladas desde los primeros estudios de la Constitución, en los primeros años de su vigencia no se apreciaba especialmente una demanda de reforma tendente a suprimir esas restricciones, o ampliar los instrumentos constitucionales de participación ciudadana. Como es sabido, ha sido mucho después, y sobre todo a raíz de la crisis económica y política que se manifiesta desde finales de la primera década 
del siglo XXI, cuando ciertos movimientos sociales han puesto sobre la mesa la necesidad de amplias reformas (o directamente de una nueva Constitución) que incidan en una mayor calidad democrática del sistema.

Son muchos los factores que han provocado estas mayores exigencias (la intensa crisis económica, el desempleo, la corrupción política demasiado generalizada, la falta de democracia interna de los partidos y los supuestos de financiación irregular, la lentitud de la justicia, los efectos del sistema electoral, entre otros), y muchas también las posibles propuestas de cambio: desde la convocatoria de una nueva constituyente que rompa con nuestro sistema constitucional, ignorando incluso los procedimientos de reforma explícitamente establecidos en los artículos 166 y siguientes, a reformas constitucionales de mayor o menor calado, que eliminen o reduzcan las restricciones a la democracia directa o introduzcan nuevos mecanismos de participación ciudadana.

A partir de las elecciones europeas de 2014, y sobre todo de las elecciones locales, autonómicas y generales de 2015, el propio sistema de partidos en España cambia, pasando del llamado «bipartidismo imperfecto» a un pluripartidismo más acusado, con al menos cuatro grandes partidos nacionales, ninguno de los cuales alcanza por sí mismo una mayoría suficiente para gobernar. En todo caso, con este cambio se van clarificando los apoyos que tienen las diversas propuestas, y en especial las que pretenden una ruptura con el actual sistema constitucional. De hecho, el eslogan «no nos representan» va siendo abandonado, y sustituido por otra serie de reivindicaciones de cambio. Lo que cabe constatar es que, como consecuencia en parte de la acción de algunos movimientos sociales, buena parte de la sociedad y de sus representantes políticos van asumiendo la necesidad de algunos cambios, que redundarían en una mejora de la calidad de nuestro sistema democrático.

Desde el punto de vista del análisis jurídico-constitucional, que es el enfoque que interesa a este trabajo, creo que se puede decir que hubo diversos factores que provocaron una crisis de confianza de los ciudadanos en sus representantes, y más ampliamente en toda la clase política. Desde luego, el problema no es solo, ni acaso principalmente, la restricción constitucional de las instituciones de participación ciudadana; pero sí parece que este factor, junto con otros (como los defectos de proporcionalidad del sistema electoral) han provocado una sensación de cierta insatisfacción con algunas características del modelo representativo actual, y una clara demanda de mayores y mejores opciones de participación ciudadana, que no solo se traduce (aunque también) en una mayor apertura de las vías de democracia directa o semidirecta, sino igualmente en una mayor intensidad de la comunicación entre electores y representantes, y en vías para la exigencia de responsabilidades a estos. Esa crisis de confianza, aunque probablemente más acentuada hace pocos años, no está aún resuelta, y acaso no puede resolverse enteramente mediante reformas constitucionales y legales. Pero estas pueden contribuir, en la medida en que tiendan a abrir canales de participación ciudadana, de comunicación entre los ciudadanos y los responsables políticos, y de responsabilidad y rendición de cuentas. 
Aunque el debate entre representación política y democracia directa vuelve a cobrar protagonismo en este contexto, tiene a mi juicio unos perfiles diferentes. En mi opinión, es incontestable el hecho de que en las democracias occidentales no cabe ya plantear, por razones sobre todo prácticas, la sustitución de la democracia representativa por un modelo de democracia directa como soñaba Rousseau, pero ello no prejuzga el valor o la importancia que en cada sistema se dé a los instrumentos de participación ciudadana directa o semidirecta. Probablemente, hoy nos encontramos unos elementos diferentes, pues no se trata abiertamente de una confrontación entre representación y democracia directa, sino entre una concepción más liberal o más activa y participativa de la democracia; algunos autores ${ }^{27}$ contraponen «democracia constitucional» de raíz liberal, frente a «democracia radical», entroncada con las ideas de Rousseau. También se ha destacado la complejidad del propio concepto de representación política ${ }^{28}$. Y hoy es muy común señalar la existencia de una crisis de la representación política, en el centro de la cual suele situarse a los partidos políticos ${ }^{29}$.

En cualquier caso, como algunos autores ${ }^{30}$ han justificado, parece necesario mantener la representación política en el contexto actual, ya que la democracia directa, además de inviable en sociedades complejas, puede resultar inconveniente para aquellos ciudadanos que prefieren encomendar a otros la gestión de los asuntos públicos para no ocuparse ellos ( «la libertad individual incluye la opción de vivir al margen de la política» ${ }^{31}$ ); además, podría resultar inadecuada a la hora de adoptar decisiones que requieren mayores debates o de aprobar normas que pueden resultar modificadas, completadas o rectificadas en aspectos parciales o de detalle, a lo largo de una tramitación parlamentaria. Como ha destacado Díez-Picazo «la democracia representativa permite el matiz y el compromiso, algo que resulta muy difícil — cuando no imposible- en la democracia directa» ${ }^{32}$.

Por tanto, y como vamos a apuntar, no se trata solo de revisar o aumentar las instituciones de democracia directa y semidirecta, sino de un conjunto de medidas que faciliten esa comunicación con los responsables políticos, así como vías para la exigencia de responsabilidades y rendición de cuentas. Son tareas cuya ejecución supondría la mejora de los canales existentes de participación, y la apertura de otros nuevos, y que suelen englobarse en el objetivo de conseguir la regeneración democrática.

27 Pendás García, B. (2016), «Las formas de la democracia», en El cronista del Estado social y democrático de Derecho, n. ${ }^{\circ}$ 60, abril. Madrid: Portalderecho, p. 18.

${ }^{28}$ Por ejemplo, García GuITIÁN, E. (2004), «El significado de la representación política», en Anuario de la Facultad de Derecho de la Universidad Autónoma de Madrid, n. ${ }^{\circ}$ 8, pp. 109 ss.

29 En esta línea, VV. AA. (2014), «Encuesta sobre la representación política», en Teoría y realidad constitucional, n. ${ }^{\circ}$ 34, 2. ${ }^{\circ}$ semestre. Madrid: UNED. Véase también el interesante trabajo de REBATO PEÑo, M. E. (2017), «La representación en el Estado democrático de partidos actual: algunas reflexiones sobre la participación política del ciudadano», en Sociedad Jurídica, n. " 4, Lima.

30 Por ejemplo, Díez-Picazo, L. M. (2014), «Apología de la democracia representativa», en Parlamento y Constitución. Anuario, n. ${ }^{\circ}$ 16. Toledo: Cortes de Castilla-La Mancha, p. 212.

31 Pendás García, B. (2016), cit., p.18.

32 Díez-PiCAzo, L.M. (2014), cit., p. 219. 


\section{LA TAREA DE LA REGENERACIÓN DEMOCRÁTICA: BUEN GOBIERNO, PARTICIPACIÓN, CONFIANZA}

No es fácil establecer un catálogo de medidas necesarias para llevar a cabo esa labor de regeneración democrática ${ }^{33}$. Sin pretensiones de exhaustividad, y teniendo en cuenta algunos aspectos señalados política y doctrinalmente, podríamos apuntar los siguientes retos o tareas, cuya realización satisfactoria contribuiría probablemente de forma decisiva a la mejora de la calidad democrática de nuestro sistema:

a) En primer lugar, y como venimos señalando, hay que implantar mecanismos tendentes a facilitar la participación de los ciudadanos en la toma de decisiones políticas, completando nuestro modelo representativo con mejores y más transitables vías de participación directa o semidirecta.

b) En segundo lugar, hay que establecer mejores vías de comunicación entre electores y representantes, procurando una mayor cercanía entre ellos, así como mecanismos que intensifiquen la receptividad (responsiveness) y posibiliten la rendición de cuentas (accountability), que contribuirán a recuperar la confianza en los representantes y en general, en la llamada «clase política». Aunque a este objetivo pueden tender muy variadas medidas, desde la implantación de primarias abiertas para elegir a los candidatos, hasta las listas abiertas, cabe apuntar especialmente la posibilidad de establecer registros de votantes y una especie de derecho de petición de estos, que obligase a los candidatos electos a responder las cuestiones o planteamientos ciudadanos ${ }^{34}$. Igualmente, en esta misma línea se apuntan algunas ideas que permiten un mayor control ciudadano sobre la actividad parlamentaria, como el llamado «parlamento abierto», «escaño ciudadano», u otras fórmulas tendentes a la participación directa de los ciudadanos en la actividad de sus representantes.

c) Adoptar medidas tendentes a fortalecer la llamada «sociedad civil», fomentando el papel de entidades intermedias entre el individuo y el Estado. Ello conllevará algunas medidas concretas que, por ejemplo, permitan regular los lobbies y sus relaciones con los poderes públicos basadas en los principios de participación y transparencia, contribuyendo a «una sociedad civil fuerte $\mathrm{e}$ independiente ${ }^{35}$, y en definitiva a un mayor protagonismo de los ciudadanos y los colectivos por ellos formados, característica propia de un sistema

33 Sobre el tema, véase por ejemplo Tur Ansina, R. (dir.) (2016), Poderes públicos y privados ante la regeneración constitucional democrática, Madrid, Dykinson.

34 Véase por ejemplo Garrorena Morales, A., «Democracia, participación y representación. La crisis actual de la democracia representativa. ¿Qué hacer?», en José Luis Cascajo Castro y Augusto Martín de la Vega (coords.), Participación, representación y democracia. XII Congreso de la Asociación de Constitucionalistas de España, Tirant lo Blanch, Valencia, 2016, especialmente págs. 84 ss.

35 Politikon (2014), La urna rota. La crisis política e institucional del modelo español, Barcelona, Debate. 4. 'a edición, p. 198. 
democrático en el que el papel de los ciudadanos no se limita a la elección de sus representantes.

d) También relacionado con lo anterior, estaría la reflexión sobre el sistema electoral adecuado, en la medida en que este puede facilitar una mayor identificación entre electores y elegidos, así como que el pluralismo social se traslade adecuadamente a la composición parlamentaria. Sin embargo, sobre esta cuestión hay dos tendencias aparentemente contradictorias: mayor proporcionalidad electoral tiende a garantizar un mayor pluralismo, o bien fórmulas mayoritarias en circunscripciones pequeñas pueden facilitar la cercanía entre electores y representantes (además de que pueden favorecer la gobernabilidad). Además, hay que considerar que, en un sistema parlamentario, el sistema electoral no solo debe tener el objetivo de reflejar el pluralismo, sino también el de favorecer la formación de gobiernos estables. Desde esta perspectiva, aunque nuestro sistema electoral para el Congreso ha sido objeto de numerosas críticas, y uno de los centros de casi todas las propuestas de reforma, conviene no olvidar que ha permitido muy diversos sistemas de partidos y resultados, desde el bipartidismo más o menos imperfecto al pluripartidismo, y desde las mayorías absolutas a gobiernos muy minoritarios. Quiero decir con ello que ha cumplido razonablemente su función, y tiene facetas positivas, lo que no significa que no deba reformarse, ya que el efecto distorsionador de la circunscripción ha generado acusadas disfuncionalidades que no tienen un objetivo o finalidad claro, y por tanto parecen carentes de justificación.

e) Facilitar la transparencia en la gestión pública, posibilitando la publicidad activa y el acceso a la información pública por los ciudadanos.

f) Establecer mecanismos para asegurar un conjunto de prácticas que se han dado en denominar de «buen gobierno», y que en definitiva implican la exigencia de comportamientos «honestos» a los servidores públicos. Aunque ciertamente el significado de esta palabra dificulta extraer consecuencias en el terreno estrictamente jurídico, es cierto que tiende a abrirse camino un concepto de honestidad pública, que en definitiva permite a la sociedad exigir responsabilidades más allá del incumplimiento de la ley.

g) Revisar las posibles prerrogativas que se reconozcan a los cargos públicos, adecuándolas a los principios de igualdad, justicia y a las exigencias del Estado de Derecho, o suprimiendo las que no encuentren sentido en este contexto, para que no se conviertan en privilegios.

h) Más ampliamente, limitar la posibilidad de que se llegue a situaciones de concentración temporal de poder, por acumulación ilimitada de períodos de tiempo o de diferentes cargos públicos, sobre todo cuando esta situación deriva principalmente del poder de los partidos políticos. La limitación de los mandatos, al menos para el caso de los presidentes, aunque es un instrumento nacido en los modelos presidencialistas, parece hoy muy conveniente en 
sistemas parlamentarios europeos, en los cuales también se ha ido destacando la preeminencia clara de la figura del presidente.

i) Garantizar la democracia interna de los partidos políticos. Es muy importante señalar que los partidos no son el problema (todas las alternativas que han intentado eliminar el pluralismo de partidos han conducido a la negación de la democracia); aunque tal vez uno de los problemas de esta crisis política sean «estos» partidos. Por eso en este ámbito hay mucho que hacer para acercar a los representantes (y antes incluso, a los candidatos y a los partidos que canalizan esa relación representativa) a la sociedad. Para empezar, desde luego, mayor democracia interna, que vendría dada con un sistema más amplio y abierto para la elección de los cargos directivos. Para seguir, mayor cercanía con la sociedad a la hora de fijar los candidatos electorales, lo cual, con todas las dificultades y cuestiones que se quieran plantear, se podría conseguir con un sistema de primarias abiertas para la elección de candidatos 36. Para avanzar más, en materia de relación con los representantes electos, habría que conseguir una mayor posibilidad de comunicación entre estos y sus votantes, que podría llevarse a cabo mediante registros de electores y fórmulas más ágiles de comunicación postelectoral ${ }^{37}$, aprovechando la ventaja que ofrecen las nuevas tecnologías, y estableciendo un auténtico derecho de los electores a la comunicación con sus representantes, lo que implicaría obligaciones en esta línea para los representantes y los propios partidos.

j) Implantar o fortalecer controles eficaces y sanciones adecuadas que puedan imponerse con cierta agilidad, de cara a evitar los abusos en la gestión de los recursos públicos, así como en la financiación de los partidos políticos, y más ampliamente todas las formas de corrupción económica en todo cargo público o representativo, y por supuesto en los partidos políticos.

k) Quizá una de las iniciativas cuya posible introducción más se ha debatido sería la posibilidad de revocar el mandato de los cargos electos. Este mecanismo de participación directa y exigencia de responsabilidad existe en algunos sistemas, sobre todo presidencialistas, respecto a los parlamentarios, y en algún caso incluso frente al presidente, con el nombre de referéndum revocatorio o acción revocatoria. Mediante este mecanismo, un número mínimo de ciudadanos pueden solicitar la revocación de los cargos para los que se considere aplicable este mecanismo, y en caso de alcanzarse ese mínimo, esa posibilidad ha de someterse a referéndum, para cuya aprobación es posi-

36 Sobre las primarias, a título de muestra, puede verse por ejemplo GAMBINO, S. (1997), «Elecciones primarias y representación política: algunas reflexiones para el debate», en Parlamento y Constitución. Anuario, n. ${ }^{\circ} 1$, pp. 117 ss.

37 En esta línea, Garrorena Morales, A. (2016), «Democracia, participación y representación. La crisis actual de la democracia representativa. ¿Qué hacer?», en CASCAJO CASTRO, J.L., y MARTíN DE LA Vega, A., Participación, representación y democracia. XII Congreso de la Asociación de Constitucionalistas de España. Valencia: Tirant lo Blanch, p. 84). 
ble que se exija algún tipo de mayoría cualificada. En caso de llevarse a cabo esa aprobación, el cese del cargo se produciría de manera obligatoria.

En mi opinión, un mecanismo de este tipo, aplicable al presidente del Gobierno, sí rompería por completo el esquema de la confianza y la responsabilidad propio de un modelo parlamentario, y de hecho implicaría un cambio de modelo, cuando menos a un sistema mixto, lo que supondría no pocos ajustes.

Sin embargo, podría considerarse la implantación de este instrumento para los cargos directamente elegidos por el pueblo, o al menos frente a los diputados y senadores. Dicha implantación permitiría a los ciudadanos cesar a cargos sobre cuyo comportamiento o actividad se ha generado un cuestionamiento ético o político, pero que no están dispuestos a abandonar el cargo, y son amparados por su partido en esa actitud. Con todo, conviene analizar la experiencia de los países que conocen estos instrumentos, que han permitido en ocasiones tergiversaciones, usos torticeros, abusos o consecuencias indeseadas, bien para con los cargos sometidos a revocación, bien para los propios firmantes de la solicitud de revocación. De hecho, este mecanismo requiere en mi opinión una elevada calidad y cultura democrática en una sociedad, para que funcione adecuadamente, y además ha de implantarse con los correspondientes controles y límites, para impedir los abusos. Además, su implantación requeriría la instauración de un sistema electoral adecuado, ya que si bien puede tener sentido en un sistema mayoritario con circunscripciones uninominales, en sistemas de listas hay que implantar garantías que impidan movimientos abusivos procedentes de una mayoría de votantes de otros partidos, lo cual implica considerar siempre la sustitución por otra persona de la misma lista, y exigir mayorías cualificadas. Por lo demás, este sistema debe venir acompañado de listas abiertas o desbloqueadas, que desde la misma elección permitan a los ciudadanos descartar a determinados candidatos.

\section{EL DESARROLLO NORMATIVO Y LAS REFORMAS LEGALES}

Apuntados los que a mi juicio son los principales retos a afrontar para mejorar la calidad de nuestra democracia (y que en mayor o menor medida son compartidos por las diversas democracias occidentales), conviene analizar si el desarrollo legal de la Constitución, con sus reformas posteriores, ha permitido avanzar en la línea apuntada. Ello tiene sentido como paso previo al análisis de la conveniencia o necesidad de reformar la Constitución para conseguir los mencionados objetivos, porque en primer lugar conviene profundizar en las posibilidades de avances mediante reformas legales, y en que medida este tipo de avances se han ido produciendo en las cuatro décadas de desarrollo constitucional.

Al analizar los diversos mecanismos de participación ciudadana recogidos en la Constitución, ya se han mencionado las principales leyes que han llevado a cabo la regulación de dichos mecanismos. Por tanto, no repetiré aquí las referencias a estas normas, sino que más bien intentaré realizar una valoración conjunta de este desarrollo. 
En síntesis, podría decirse que el desarrollo ha sido insuficiente, y quizá en alguna medida la causa esté en que es la propia Constitución la que impide una regulación más abierta y favorable a la participación. Como se ha visto por ejemplo en el caso del referéndum o la iniciativa legislativa popular, las leyes de desarrollo han de contar con las propias restricciones que la Constitución establece, y aunque eventualmente esta pueda permitir en algún punto un desarrollo más favorable a la participación, tampoco el margen es muy grande.

Un caso en parte diferente es el relativo a la reforma electoral, que si bien puede llevarse a cabo con la Constitución actual, ya que esta permite diversos modelos y alternativas, creo que si no se procede a una modificación de la Constitución, la reforma tendría que afrontar algunos condicionamientos que no resultarían positivos prácticamente en ningún sistema proporcional, como es por ejemplo la circunscripción provincial. Por ello sería preferible también una previa reforma constitucional en algunos aspectos, aunque como he apuntado, en caso de que esta no se llevase a cabo, quizá podría explorarse la medida adecuada de una reforma legal del régimen electoral, a pesar de que esta no podría solventar algunas dificultades relevantes, derivadas de algunos parámetros constitucionales.

En cuanto a otras medidas apuntadas, si bien en algunos casos podrían introducirse mediante reformas legales (tal vez la revocación de cargos electos, o algunas medidas tendentes a la rendición de cuentas), la mayoría de estas medidas de regeneración democrática o requieren incuestionablemente reforma constitucional (por ejemplo, la eliminación de las prerrogativas parlamentarias), o sería altísimamente conveniente dicha reforma, para evitar incluso dudas sobre la constitucionalidad de la medida (limitación de los mandatos). En cualquier caso, al tratarse de un conjunto de medidas de máximo calado y gran trascendencia, la reforma constitucional se hace globalmente imprescindible.

Pero tampoco sería justo terminar este apartado con la idea de que no se han aprobado medidas legislativas tendentes a favorecer la comunicación, la información o la regeneración democrática. En este sentido, cabe citar especialmente la Ley de Transparencia, Acceso a la Información y Buen Gobierno, así como la legislación autonómica en la materia. Con independencia de críticas que puedan hacerse, creo que hay que señalar que esta legislación introduce garantías importantes en lo relativo a la publicidad activa, el acceso a la información, así como determinadas medidas para intentar asegurar comportamientos adecuados de los cargos públicos, o al menos impedir aquellos no acordes con los actuales niveles de exigencia ética y política de la sociedad.

\section{LA REFORMA CONSTITUCIONAL}

De todo lo anterior se deriva la necesidad de llevar a cabo una reforma de la Constitución, que tendría cierta amplitud en lo relativo al modelo de democracia, y a la 
participación ciudadana. Lo cual, añadido a otros muchos aspectos que parecen necesitar una reforma, conduciría probablemente a una modificación amplia que afectaría a casi todos los títulos de la Constitución ${ }^{38}$ (aunque, en mi opinión, no sería conveniente una revisión total, porque los valores y principios fundamentales de la Constitución han de mantenerse, dado que siguen vigentes en la actualidad, y son la base de la legitimidad material del propio sistema constitucional).

Aunque se deduce de lo anteriormente analizado, creo que la reforma habría de ir en dos sentidos:

a) Una nueva regulación de las instituciones de democracia directa y semidirecta que ya están previstas en la Constitución (sobre todo, referéndum e iniciativa legislativa popular), para eliminar sus restricciones injustificadas y facilitar su ejercicio. Así, cabría permitir el referéndum sobre normas, e incluso establecer en tal caso su carácter vinculante; permitir el referéndum abrogatorio; e introducir la iniciativa popular para la convocatoria de estos referéndums, aunque se introduzcan porcentajes significativos y otras cautelas para evitar la instrumentalización del referéndum. También sería positivo flexibilizar la posible celebración de referéndums en una parte del territorio, y aumentar el margen de las Comunidades Autónomas en la materia.

En cuanto a la iniciativa popular, permitirla para la reforma constitucional, bajar el número de firmas necesario; revisar a la baja las materias sobre las cuales no cabe esta iniciativa (por ejemplo, permitirlo en bloque en materias propias de Ley Orgánica), y garantizar de algún modo que, salvo que se in-

38 Existe ya una muy abundante bibliografía sobre la reforma constitucional, y en especial sobre materias susceptibles de reforma en la Constitución española, que se inicia hace décadas, y no es posible recoger aquí, aunque hay que mencionar al menos los trabajos casi «clásicos» de DE VEGA GARCíA, P. (1985), La reforma constitucional y la problemática del Poder Constituyente, Madrid, Tecnos, y PÉrez Royo, J. (1987), La reforma de la Constitución, Madrid, Congreso de los Diputados. Hasta 2004, consúltese el trabajo de Belda PÉrez-Pedrero, E. (2004), «Materiales doctrinales para la reforma constitucional en España» en Parlamento y Constitución. Anuario, n. ${ }^{\circ}$ 8, pp. 185 ss. Muy interesante a estos efectos es también el Boletín de Documentación n. ${ }^{\circ}$ 19-20, 2004, del Centro de Estudios Políticos y Constitucionales, dedicado a La reforma constitucional en España. Como parte del intento de reforma de la VIII Legislatura, hay que mencionar Rubio Llorente, F., y Álvarez Junco, J. (eds.) (2006), El informe del Consejo de Estado sobre la reforma constitucional: texto del informe y debates académicos, Madrid, Consejo de Estado-Centro de Estudios Políticos y Constitucionales. Un análisis de dicho proceso puede verse en Belda Pérez-Pedrero, E. (2008), La fallida reforma de la Constitución española durante la VIII Legislatura (2004-2008), Madrid, Thomson-Civitas. También hay que destacar un muy interesante y completo estudio sobre la reforma constitucional en el constitucionalismo histórico español y en la Constitución de 1978: Vera Santos, J. M. (2007), La reforma constitucional en España, Madrid, La Ley, o Vera SAntos, J.M. y Díaz Revorio, F. J. (2009), La reforma estatutaria y constitucional, Madrid, La Ley, 2009. Más recientemente, entre los trabajos colectivos que analizan perspectivas y posibilidades para una posible reforma futura, destaca Álvarez CONDE, E. (dir.) (2017), Reflexiones y propuestas sobre la reforma de la Constitución española, Granada, Comares. 
cumplan los requisitos de procedimiento o materiales, el Congreso deba al menos debatir sobre el fondo de la iniciativa ${ }^{39}$.

b) Suprimir la inmunidad y el fuero especial de los parlamentarios.

c) La introducción de mecanismos tendentes a mejorar la calidad democrática, intensificar la participación ciudadana y favorecer los controles de los poderes públicos y de las personas que ostentan cargos públicos: introducción de la limitación de los mandatos del presidente, o por mejor decir del período en que puede serlo, a ocho años consecutivos; considerar la posibilidad de introducir, con ciertas garantías, la revocación del mandato de los cargos representativos.

d) Revisar los preceptos constitucionales relativos al sistema electoral, en particular en lo que atañe a la circunscripción del Congreso y del Senado.

e) Exigir, más allá de la democracia interna de los partidos políticos, formas de elección de sus representantes, y de los candidatos a presidentes, que permitan la participación directa de todos los afiliados, y en su caso de los simpatizantes.

f) Reconocer expresamente, como derecho fundamental, el derecho de acceso a la información pública.

\section{CONCLUSIONES}

Con todo, es evidente que ni siquiera la reforma constitucional, aunque venga posteriormente acompañada de las reformas legales que la desarrollen o introduzcan otros aspectos (financiación de los partidos, nueva regulación de los propios partidos políticos, controles contables...), garantiza un proceso exitoso de regeneración democrática. Hay cambios sociales y culturales, además de económicos, que hay que asumir.

En todo caso, y desde la perspectiva constitucional que aquí interesa, esas reformas pueden ser la base para intentar superar los problemas que nuestra democracia ha afrontado, en parte por la falta de comunicación, transparencia y exigencia de responsabilidades a los representantes políticos; en parte también porque, una vez elevado el rasero de la calidad democrática y la participación ciudadana, que en 1978 estaba bastante bajo, se ha implantado ampliamente la sensación de que los ciudadanos tienen pocas opciones de participar directamente en la toma de decisiones, ser consultados y escuchados, o mantener una comunicación más directa con sus representantes.

39 En esta línea, por ejemplo, Cabello Fernández, M. D. (2017), Democracia directa..., cit., p. 135, propone suprimir el trámite de toma en consideración en este tipo de iniciativas. Lo cual, por cierto, puede lograrse sin necesidad de reforma constitucional, porque no deriva de la norma fundamental, sino de la Ley que actualmente regula la iniciativa legislativa popular. 
No se trata, desde luego, de sustituir nuestro modelo representativo por otro (inviable a todos los efectos) de democracia directa; pero sí de hacer más participativa y abierta nuestra democracia. La dialéctica más importante no se produce ahora entre democracia representativa y democracia directa, sino entre partidos políticos y ciudadanos como protagonistas de la relación representativa. Hay mucho que hacer para volver a dar el protagonismo político a los ciudadanos, pero creo que los partidos políticos, aun no siendo un elemento que haya acompañado a la democracia en toda su historia, sí lo han hecho durante la Edad Contemporánea, de manera que pueden considerarse consustanciales al modelo de representación política que comienza con ella. Como ha destacado Velasco Retamosa ${ }^{40}$, en la actualidad es difícil hablar de democracia sin partidos políticos, pero es imposible considerar a los partidos como elementos de la democracia si estos no funcionan en sintonía con el objetivo de servir a esta. Desde los orígenes de los actuales sistemas constitucionales, todos los modelos que han querido prescindir de los partidos como instrumento para la canalización de la relación representativa, lejos de mejorar la calidad democrática, han roto con la propia idea de democracia pluralista.

Dicho lo anterior, se trata de mejorar para evitar las distorsiones que se han ido produciendo. Y hay, en este ámbito, mucha tarea por hacer. Por un lado, en lo relativo a la participación directa de los ciudadanos y, por otro, en lo que atañe a las relaciones entre electores y representantes.

Comenzando por lo primero, frente a la democracia representativa que podríamos denominar «convencional» se viene hablando de democracia participativa, democracia deliberativa y democracia inclusiva ${ }^{41}$. La primera propugna la intensificación de las vías de participación ciudadana directa, estableciendo mayores espacios abiertos a dicha participación. La segunda defiende unas condiciones ideales en las que es posible la adopción de decisiones tras un debate público de ciudadanos libres, iguales y bien informados. La tercera, en cambio, propugna asignar cuotas de representación a colectivos minoritarios, y llevada a su extremo supondría una ruptura con la idea de la representación política, en la que la cámara parlamentaria representa a la nación (o actualmente diríamos, a todo el pueblo). Por su parte, la democracia deliberativa es un modelo ideal, un desiderátum, que sin embargo puede servir como referencia importante para implantar cambios sociales y culturales, los cuales requerirán sobre todo una mejor educación ciudadana que conducirá a sociedades más capacitadas y activas, capaces de adoptar decisiones (ya sea por vía directa o representativa) con mucha mayor información y con criterios muchos más fundados.

Pero es probablemente la democracia participativa la idea que más interés tiene desde la perspectiva de la calidad democrática. Descartada la democracia directa, el contexto actual permite abrir un mayor ámbito para la participación ciudadana en la

40 Velasco Retamosa, J. M. (2013), «Democracia y partidos políticos», en Valmaña Ochaíta, A. (coord.), Democracia en el mundo antiguo y en la actualidad, Granada, Andavira, p. 223.

41 Por ejemplo, Pendás García, B. (2016), cit., 22. 
toma de decisiones, gracias sobre todo a los instrumentos que brindan las nuevas tecnologías. Ciertamente, todos los sistemas representativos han contado siempre con elementos de democracia directa o semidirecta, como el referéndum, la iniciativa legislativa popular o, en ámbitos locales muy reducidos, el concejo abierto. Hoy en día estos elementos pueden utilizarse de forma más ágil y con mayor frecuencia, eso sí, intentando conjurar los riesgos que pueden tener en cuanto a instrumentalización, que serían mucho menores en el contexto de una cultura deliberativa y participativa, con posibilidad de acceso a la información y de debates abiertos y transparentes.

Pero más allá de flexibilizar estos instrumentos de democracia directa, la regeneración democrática demanda en este ámbito que los ciudadanos, individual o colectivamente, puedan participar más activamente en la «vida política, económica, cultural y social», algo que corresponde a los poderes públicos «facilitar», por utilizar la terminología del artículo 9.2 de la Constitución española. Desde luego, ya existen las vías de los derechos fundamentales con una vertiente más participativa, desde la propia libertad de expresión (hoy quizá ha ido pasando ya de ser una «libertad burguesa», o un derecho mucho más accesible y democrático que nunca gracias a internet) a las libertades de manifestación o asociación, o la propias libertades religiosa o sindical en sus vertientes colectivas. Pero una mayor calidad democrática puede conseguirse, más allá del reconocimiento de estas posibilidades, facilitando su ejercicio y potenciando el papel de las entidades resultantes (asociaciones, sindicatos, comunidades, y más ampliamente todo tipo de movimientos ciudadanos que pretendan jugar un papel en la vida social).

Pero además de los mecanismos de democracia directa y del mayor protagonismo de la sociedad civil, y desde luego con una importancia no menor que estos elementos, aparece la necesidad de establecer una comunicación más ágil y sencilla entre electores y representantes, con la exigencia de que estos rindan cuentas no solo en los supuestos de responsabilidades legales (casos de infracciones del ordenamiento) o políticas, sino de una manera más habitual y cotidiana. En este punto, es común señalar que los partidos políticos han constituido muchas veces un obstáculo para esa comunicación directa entre representantes y representados, al establecer una especie de «barrera» o de nuevo «mandato imperativo» que merma enormemente las posibilidades de actuación o iniciativa individual de los parlamentarios. Estos, en realidad, sienten casi siempre más necesidad de satisfacer a la estructura del partido que les posicionó en la lista electoral, que a los votantes que apoyaron dicha lista. Ciertamente, los partidos políticos son un elemento de la representación contemporánea que viene a romper los esquemas tradicionales de la representación parlamentaria original, pero desde luego esta circunstancia, profunda y antigua, por un lado, no explicaría por sí misma la actual crisis de confianza, y por otro puede superarse o paliarse con otro modelo de partidos y de relaciones electores-representantes.

Hay, en suma, una labor ingente que hacer para mejorar la calidad democrática y facilitar la participación ciudadana. La Constitución de 1978 ha desempeñado un papel fundamental, garantizando el período democrático más largo de nuestra histo- 
ria. Sus valores fundamentales siguen vigentes, y muchas de sus regulaciones son todavía aplicables a la situación actual. Pero otras no tanto, de manera que la reforma constitucional, sin que pueda en sí misma resolver todos estos problemas, ha pasado ya de ser conveniente, a resultar muy necesaria. La sociedad ya no se conforma con un modelo democrático basado en la mera elección de representantes entre opciones políticas plurales, pero a los cuales no se les puede exigir responsabilidad, ni rendición de cuentas. Los ciudadanos quieren, por un lado, contar con vías más accesibles de participación directa, y por otro, tener una comunicación más fluida con sus representantes, y que estos estén sometidos en su actuación a mayores límites y controles. Una amplia reforma constitucional ayudaría a ello, y probablemente contribuiría a prolongar la vigencia y actualidad de la Constitución otras cuantas décadas.

\section{Title:}

Democracy, Representation and Citizen Participation, in search of a balance that 1978 Constitution did not achieve

\section{Summary:}

1. Representative democracy, direct democracy institutions, and citizen participation in Spanish Constitution: context and conditioning factors. 2. Some citizen participation institutions. 2.1. Referendum. 2.2. Popular initiative of Law. 2.3. The open council. 2.4. Participation in Administration. 2.5. The jury and others. 3. Four decades later, a crisis of confidence? 4. The task of democratic regeneration: good governance, participation, trust. 5. Development and legal reforms. 6. A task always pending: constitutional reform. 7. Conclusions

\section{Resumen:}

A la hora de regular el modelo de democracia y los mecanismos de participación ciudadana, la Constitución de 1978 fue conformista y prudente. Estableció un modelo de democracia representativa basado en la posibilidad de elegir representantes cada cuatro años, pero sin especiales fórmulas de control y exigencias de responsabilidad política hacia ellos. Por lo demás, estableció una regulación restrictiva de los instrumentos de democracia directa y semidirecta, en especial del referéndum y de la iniciativa legislativa popular.

Cuatro décadas después, las exigencias ciudadanas se han intensificado, generándose un cierto déficit de confianza entre electores y representantes. 
El trabajo analiza los principales déficits de la Constitución de 1978 en la materia, realizando varias propuestas para mejorar la calidad democrática, que en buena parte implican una amplia reforma constitucional: eliminar las restricciones constitucionales del referéndum y la iniciativa popular, incorporar vías de exigencia de responsabilidad y rendición de cuentas, limitar los mandatos del presidente, asegurar la democracia interna de los partidos políticos, eliminar algunas prerrogativas de los parlamentarios, entre otros.

\begin{abstract}
:
When regulating the model of democracy and the mechanisms of citizen participation, the Constitution of 1978 was conformist and prudent. It established a model of representative democracy based on the possibility of electing representatives every four years, but without special formulas of control and demands of political responsibility towards them. Moreover, it established a restrictive regulation of the instruments of direct and semi-direct democracy, especially the referendum and popular legislative initiative.

Four decades later, citizen demands have intensified, generating a certain lack of trust between voters and representatives. The paper analyzes the main deficits of the 1978 Constitution in the matter, making several proposals to improve the democratic quality, which in large part imply a broad constitutional reform: eliminate the constitutional restrictions of the referendum and popular initiative, incorporate channels of exigency of responsibility and accountability, limiting the president's mandates, ensuring the internal democracy of political parties, eliminating some prerogatives of parliamentarians, among others.
\end{abstract}

\title{
Palabras clave:
}

Democracia; regeneración; referéndum; iniciativa popular; concejo abierto; participación; ciudadano; responsabilidad.

\section{Key words:}

Democracy; referendum; regeneration; popular initiative; open council; participation; citizen; responsibility. 